\title{
Retrograde Transvenous Obliteration of Gastric Varices using Sodium Tetradecyl Sulphate: Technical Considerations and Results from a Single Institution Retrospective Study
}

\author{
Pushpinder S. Khera ${ }^{1, \odot}$ Pawan K. Garg ${ }^{1, \odot}$ Sarbesh Tiwari ${ }^{1, \odot} \quad$ Narendra Bhargava ${ }^{2}$ Taruna Yadav ${ }^{1}$ \\ Binit Sureka ${ }^{1, \odot}$ Tushar Ghosh ${ }^{1, \odot}$ Santhosh Babu ${ }^{1}$ Sunil Dadhich ${ }^{2, \odot}$ Surjit Singh ${ }^{3, \odot}$
}

\author{
${ }^{1}$ Department of Diagnostic and Interventional Radiology, All India \\ Institute of Medical Sciences, Jodhpur, Rajasthan, India \\ 2Department of Gastroenterology, Dr S N Medical College, Jodhpur, \\ Rajasthan, India \\ ${ }^{3}$ Department of Pharmacology, All India Institute of Medical \\ Sciences, Jodhpur, Rajasthan, India \\ J Clin Interv Radiol ISVIR 2021;6:10-17.
}

Address for correspondence Pawan K. Garg, MD, Department of Diagnostic and Interventional Radiology, All India Institute of Medical Sciences, Jodhpur 342005, Rajasthan, India (e-mail: drgargpawan@gmail.com).

\author{
Abstract \\ Keywords \\ - bleeding gastric \\ varices \\ - retrograde transve- \\ nous obliteration \\ - balloon-occluded ret- \\ rograde transvenous \\ obliteration \\ - plug-assisted retro- \\ grade transvenous \\ obliteration \\ - gastrorenal shunt \\ - hepatic \\ encephalopathy \\ - sodium tetradecyl \\ sulfate
}

\begin{abstract}
Introduction Retrograde transvenous obliteration (RTO) with the assistance of a balloon (BRTO) or a vascular plug (PARTO) is an established method for treating gastric varices (GVs) secondary to portal hypertension. Most of the available studies on RTO have used lipiodol along with sclerosing agents like ethanolamine oleate or sodium tetradecyl sulfate (STS). We evaluated the safety and efficacy of RTO for treating GVs using STS as a sclerosant without lipiodol.

Materials and Methods Sixteen patients (nine men, age range 16-74 years) were included in this retrospective study. Twelve patients presented with acute bleeding, two with chronic bleeding, one with large varices without bleeding, and one with refractory hepatic encephalopathy (HE). BRTO was attempted in 14 patients and PARTO in 2 patients. The technical and clinical success and complications of RTO were studied.

Results The RTO procedure was technically successful in 14 (14/16, 87.5\%) patients, with $13(13 / 14,93 \%)$ obtaining clinical success. One patient died due to the early recurrence of bleeding. Three patients had minor intraprocedural complications.

Conclusion Retrograde gastric variceal obliteration using STS is safe and technically feasible with high technical and clinical success and low complication rate.
\end{abstract}

\section{Introduction}

Approximately one in every six patients with portal hypertension develops gastric varices (GVs) due to hepatofugal flow into the gastric veins. ${ }^{1}$ Although they bleed less commonly, bleeding from GVs has higher mortality (45\%) and morbidity compared with bleeding oesophageal varices (EVs), and they are more difficult to manage endoscopically. ${ }^{1,2}$ The efferent channel for GVs is mostly a gastrorenal shunt (GRS), which opens into the left renal vein (LRV). Balloon-occluded published online May 17, 2021
DOI https://doi.org/

$10.1055 / \mathrm{s}-0041-1728998$ ISSN 2457-0214

\footnotetext{
(C) 2021. Indian Society of Vascular and Interventional Radiology. This is an open access article published by Thieme under the terms of the Creative Commons Attribution-NonDerivative-NonCommercial-License, permitting copying and reproduction so long as the original work is given appropriate credit. Contents may not be used for commercial purposes, or adapted, remixed, transformed or built upon. (https://creativecommons.org/licenses/by-nc-nd/4.0/). Thieme Medical and Scientific Publishers Pvt. Ltd. A-12, 2nd Floor, Sector 2, Noida-201301 UP, India
} 
retrograde transvenous obliteration (BRTO) of GVs involves accessing the GRS to temporarily occlude its outflow using a balloon catheter and injecting a sclerosant within the varix in a retrograde manner to induce thrombosis and thereby obliterate the varices. A schematic diagram depicting a BRTO procedure is shown in (-Fig. 1). In addition, BRTO has also been described to be of value in cases of recalcitrant hepatic encephalopathy (HE) by occluding the GRS. ${ }^{3}$ The authors report their experience on the use of sodium tetradecyl sulfate (STS) as the sclerosant during RTO of GVs in 16 patients with portal hypertension over a 4-year period.

\section{Materials and Methods}

Institutional ethical committee approval was obtained for this retrospective evaluation of patient records with consent waiver. Between February 2016 and April 2020, 16 patients had undergone RTO, of which 14 underwent BRTO and 2 underwent plug-assisted retrograde transvenous obliteration (PARTO) (-Table 1). In patients who presented with acute upper gastrointestinal (GI) bleed, the procedure was performed within 2 hours to 3 days of clinical presentation. The time duration of procedure after endoscopy depended on the hemodynamic stability and presence of active bleeding on endoscopy. The exclusion criteria for RTO is the presence of gross ascites and main portal vein (MPV) thrombosis. ${ }^{4}$

\section{Patients and Clinical Presentation}

Sixteen patients (9 men and 7 women), with a mean age of 50.9 years (age range 16 to 73 years) had undergone BRTO at our hospital over a 4-year period. Of these patients, 12 presented with an acute upper GI bleed, 2 had previous

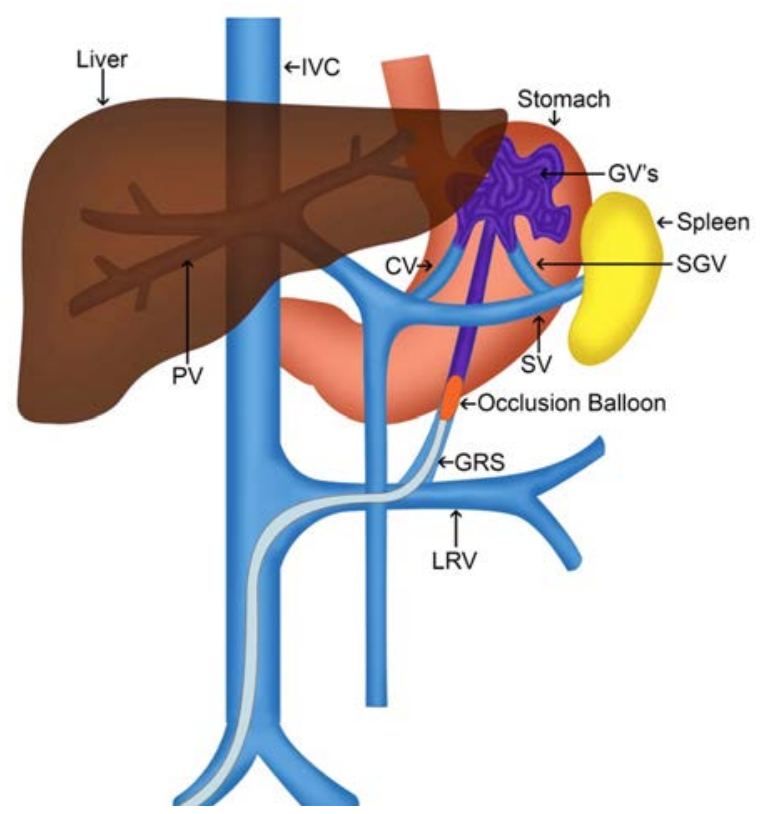

Fig. 1 Schematic diagram showing the placement of the occlusion balloon catheter (white catheter) within the gastrorenal shunt (GRS) with percolation of the sclerosant (violet areas) within the varices. The coronary vein (CV) and short gastric veins (SGVs) form the afferent for the gastric varices (GVs), whereas the GRS is the efferent. episodes of upper GI bleed with large ( $>2 \mathrm{~cm}$ size) GVs on endoscopy but were asymptomatic at the time of BRTO, 1 patient underwent the procedure prophylactically because of large GVs, and 1 had refractory HE.

The cause of liver cirrhosis in the patient group $(n=16)$ was as follows: hepatitis $B$ virus $(n=6)$, chronic alcohol abuse $(n=4)$, nonalcoholic steatohepatitis (NASH) $(n=4)$, extrahepatic portal venous obstruction (EHPVO) $(n=1)$, and cryptogenic $(n=1)$. Twelve patients were in Child B stage, 2 in Child $C$ and 2 in Child A. All patients referred for bleeding had undergone upper $\mathrm{GI}$ endoscopy for confirming the diagnosis. Endoscopic N-butyl cyanoacrylate (NBCA) glue injection had been attempted in one patient prior to referral for RTO, but no clinical improvement was noted after the same.

BRTO was attempted in 14 and PARTO was attempted in 2.

Contrast-enhanced computed tomography (CECT) of the abdomen was performed in all patients on a 128 slice CT scanner (Somatom Flash, Siemens, Erlangen, Germany) using Iohexol $300 \mathrm{mgI} / \mathrm{mL}$ as intravenous (IV) contrast material, which was injected by a pressure injector with 50 to 60-second scan delay, to assess for the following: liver volume, presence, anatomy and number of GRS, size of GVs, any large systemic efferent collaterals apart from GRS, patency of MPV and splenic vein (SV), and presence and severity of ascites.

\section{BRTO Procedure}

The right common femoral vein was accessed using a micropuncture set (Cook Medicals, USA) under local anesthesia and ultrasound guidance. Additional right internal jugular and left common femoral venous accesses were obtained for the two patients who underwent PARTO. A large-bore sheath (10 or $12 \mathrm{Fr}$ sheath, Cook Medicals, USA) was advanced into the infrarenal IVC, and a 5 Fr catheter (Cobra 1/Davis/Headhunter 1, Cook, Medicals, USA) with a glidewire (0.035" diameter, Terumo, Japan) was used to access the LRV and subsequently the GRS. The catheter was exchanged for an occlusion balloon catheter (7.5 Fr Swan Ganz, Edwards Lifesciences, USA) in 13 patients. A $27 \mathrm{~mm}$ Equalizer occlusion catheter (Boston Scientific, USA) was used in one patient with a very large shunt measuring $25 \mathrm{~mm}$.

An occlusion venogram was obtained and was assessed for adequacy of sealing by the balloon, contrast filling the varices, and systemic communication to inferior phrenic veins/pericardiophrenic veins ( $\mathbf{- F i g}$. 2A). If pericatheter leak into the renal vein was noted, the balloon was deflated, placed in another location, and the process was repeated.

Coils/gelfoam slurry was injected to block any systemic efferent veins other than GRS. If the coiling of these veins was needed, it was performed using a microcatheter (Progreat, Terumo, Japan).

After confirming adequate stasis of contrast material within the varices with no systemic runoff, sclerosant injection was started (-Fig. 2B). We compared the variceal filling on occlusion venogram with the corresponding preprocedure coronal CT venogram ( - Fig. 2C). The embolization mixture consists of an equal volume of STS (3\% w/v sodium tetradecyl sulfate, Samarth Life Sciences, Mumbai, 
Table 1 Demographic and clinical details of the patients

\begin{tabular}{|c|c|c|c|c|c|c|c|c|c|c|}
\hline Case & $\begin{array}{l}\text { Age } \\
\text { (years) }\end{array}$ & Sex & $\begin{array}{l}\text { Cause of } \\
\text { cirrhosis }\end{array}$ & $\begin{array}{l}\text { Indication } \\
\text { for BRTO }\end{array}$ & $\begin{array}{l}\text { Hemodynamic } \\
\text { status }\end{array}$ & CPS & $\begin{array}{l}\text { STS } \\
\text { volume } \\
\text { used }(\mathrm{mL})\end{array}$ & $\begin{array}{l}\text { Technical } \\
\text { success }\end{array}$ & $\begin{array}{l}\text { Follow-up } \\
\text { period } \\
\text { (days) }\end{array}$ & Clinical result \\
\hline 1 & 73 & $M$ & HBV & $\begin{array}{l}\text { Electively } \\
\text { for chronic } \\
\text { bleeding }\end{array}$ & Stable & B8 & 0 (Failed) & No & $\begin{array}{l}\text { Lost to } \\
\text { follow up at } \\
7 \text { days }\end{array}$ & NA \\
\hline 2 & 69 & $M$ & HBV & Acute bleed & Stable & A6 & 8 & Yes & 945 & No rebleed \\
\hline 3 & 58 & M & HBV & Acute bleed & Unstable & B8 & 9 & Yes & 975 & No rebleed \\
\hline 4 & 65 & $\mathrm{~F}$ & $\mathrm{NASH}$ & Acute bleed & Unstable & C10 & 10 & Yes & 770 & No rebleed \\
\hline 5 & 74 & $\mathrm{~F}$ & NASH & Acute bleed & Stable & C10 & 11 & Yes & 190 & No rebleed \\
\hline 6 & 60 & $M$ & Alcohol & Acute bleed & Stable & B8 & 8 & Yes & 120 & $\begin{array}{l}\text { Died due to progres- } \\
\text { sion of CLD at } \\
4 \text { months, no } \\
\text { rebleed occurred }\end{array}$ \\
\hline 7 & 55 & $M$ & NASH & $\mathrm{HE}$ & Stable & B9 & 12 & Yes & 1082 & No episode of HE \\
\hline 8 & 37 & $M$ & Alcohol & Acute bleed & Stable & B7 & 10 (PARTO) & Yes & 1062 & $\begin{array}{l}\text { No rebleed, mild } \\
\text { ascites present }\end{array}$ \\
\hline 9 & 60 & $M$ & Alcohol & Acute bleed & Stable & B8 & 9 & Yes & 360 & $\begin{array}{l}\text { No rebleed, died } \\
\text { after } 1 \text { year due } \\
\text { to myocardial } \\
\text { infarction }\end{array}$ \\
\hline 10 & 16 & $\mathrm{~F}$ & EHPVO & \begin{tabular}{|l|} 
Electively \\
due to large \\
varices
\end{tabular} & Stable & B7 & 13 & Yes & 914 & $\begin{array}{l}\text { No rebleed, features } \\
\text { of hypersplenism } \\
\text { present }\end{array}$ \\
\hline 11 & 62 & $\mathrm{M}$ & Alcohol & Acute bleed & Unstable & B9 & 7 & Yes & 0 & $\begin{array}{l}\text { Died due to rebleed } \\
\text { at } 2 \text { hours }\end{array}$ \\
\hline 12 & 30 & $\mathrm{~F}$ & Cryptogenic & $\begin{array}{l}\text { Electively } \\
\text { for chronic } \\
\text { bleeding }\end{array}$ & Stable & B8 & 8 & Yes & 530 & $\begin{array}{l}\text { No rebleed, banding } \\
\text { done for oesopha- } \\
\text { geal varices at } \\
6 \text { months, mild } \\
\text { ascites present }\end{array}$ \\
\hline 13 & 16 & $\mathrm{M}$ & HBV & Acute bleed & Stable & B7 & 11 (PARTO) & Yes & 410 & No rebleed \\
\hline 14 & 33 & $\mathrm{~F}$ & HBV & Acute bleed & Stable & B9 & 0 (Failed) & No & 21 & $\begin{array}{l}\text { Endoscopic glue } \\
\text { injected at day } 4, \\
\text { rebleed at day } 21 \\
\text { and later died }\end{array}$ \\
\hline 15 & 67 & $\mathrm{~F}$ & HBV & Acute bleed & Stable & B8 & 8 & Yes & 120 & No rebleed \\
\hline 16 & 40 & $\mathrm{~F}$ & NASH & Acute bleed & Stable & A6 & 9 & Yes & 150 & No rebleed \\
\hline
\end{tabular}

Abbreviations: BRTO, balloon-occluded retrograde transvenous obliteration; CLD, chronic liver disease; CPS, Child-Pugh score; EHPVO, extrahepatic portal venous obstruction; HBV, hepatitis B virus; HE, hepatic encephalopathy; NASH, nonalcoholic steatohepatitis; PARTO, plug-assisted retrograde transvenous obliteration; STS, sodium tetradecyl sulfate.

India) and nonionic contrast material (Iohexol $300 \mathrm{mg} \mathrm{I} / \mathrm{mL}$ ) along with a few pledgets of gelfoam (absorbable gelatin sponge, USP, Reliance life Sciences, Ahmedabad, India), which were mixed using the Tessari method by way of a three-way connector.

The necessary amount of sclerosant to be injected was estimated using the initial volume of contrast material that was used to obtain the occlusion venogram. An average of $9.5 \mathrm{~mL}$ of STS was used in each procedure which along with an equal volume of contrast material was a total volume of $20 \mathrm{~mL}$ of embolization mixture. Any reflux into the MPV and SV was avoided. The balloon was kept inflated in place for approximately 6 hours and was removed under fluoroscopic guidance.
The technical success of BRTO was defined as the ability to cannulate the GRS with successful inflation of a balloon for the required period. The authors failed to do BRTO in 2/16 patients due to failure to secure a good position for occluding the GRS with the balloon.

\section{Plug-Assisted Retrograde Transvenous Obliteration (PARTO)}

Two patients underwent a PARTO of the GRS due to the large size and peculiar anatomy of the shunt. In these cases, an Amplatzer vascular plug - AVP II (St Jude, USA) was deployed using a 10 Fr sheath (Cook, USA), while a 5 Fr catheter was placed distal to it within the shunt. After confirming the complete blockage of the GRS by the plug (by obtaining an occlusion venogram), STS, gelfoam, and contrast mixture was 


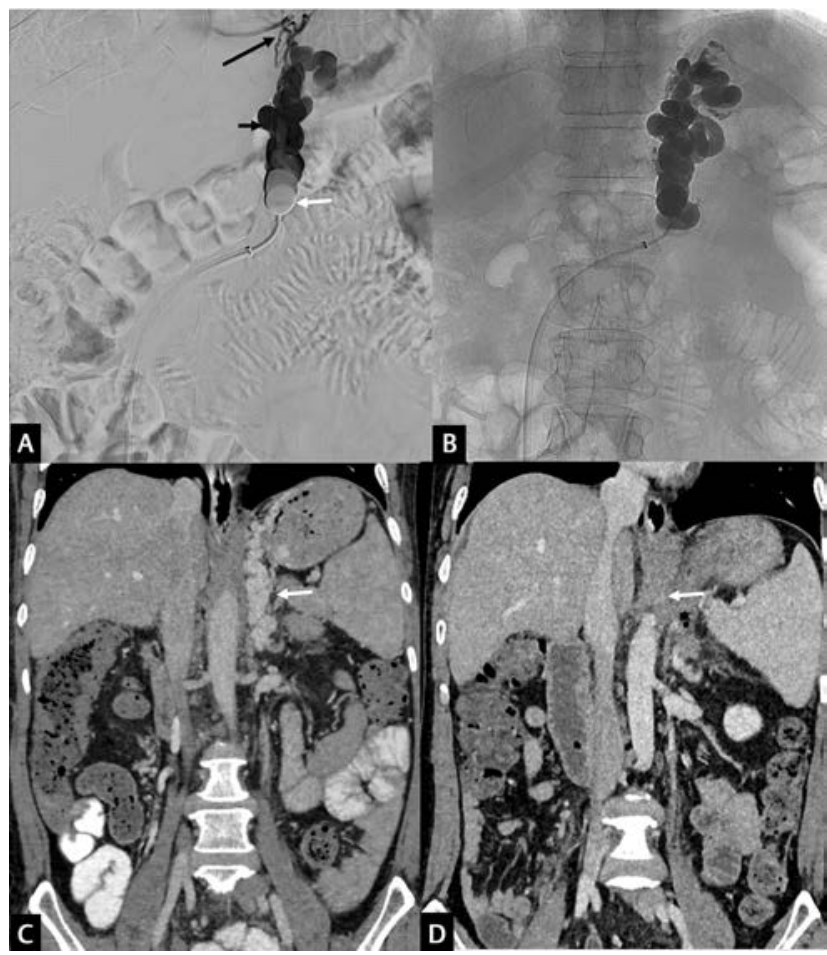

Fig. 2 (A) An occlusion venogram after placement of balloon (white arrow) in gastrorenal shunt (GRS) shows systemic runoff of contrast material into inferior phrenic and pericardiophrenic veins (black long arrow) and only partial filling of the gastric varices (GVs) (black short arrow). (B) Repeat occlusion venogram after gelfoam injection shows no systemic runoff and complete opacification of GVs (comparable with the coronal image of preprocedure CT venogram). Preprocedure (C) and 24 hours postprocedure (D) coronal CT venogram images showing patent and thrombosed GVs, respectively (white arrows).

injected through the $5 \mathrm{Fr}$ catheter. Once there was adequate stasis in the varices, the plug was deployed, and the $5 \mathrm{Fr}$ catheter was withdrawn (-Fig. 3A-E).

\section{Post-BRTO Follow-Up}

All patients underwent a CECT after 24 hours of BRTO/PARTO to assess for thrombosis of varices ( $\sim$ Figs. 2D and 3F). Clinical success was defined as nonrecurrence of bleeding from GVs.

The patients who underwent BRTO for acute/chronic bleeding were followed for any episodes of rebleed, and endoscopy was performed 1-month postprocedure. CT scan were done for all patients at 3 months with regular clinical follow-up at 3, 6, 12 months and beyond. For a single patient undergoing BRTO for hepatic encephalopathy, serum ammonia levels were evaluated at 3 months, 6 months, and 1 year.

Complications were defined as per the Society of Interventional Radiology (SIR) guidelines. ${ }^{5}$ Minor complications were defined as those requiring minimal or no therapy. Major complications were defined as those requiring prolonged hospital stay or leading to irreversible adverse sequelae.

\section{Statistical Analysis}

The probability of overall survival rates, ascites-free survival rates, and bleed-free survival rates were estimated using the Kaplan-Meier method. Statistical analysis was performed using the statistical package SPSS 21.0 for Windows (SPSS Inc., Chicago, IL, USA). The pooled estimates of technical success and 1-year overall survival rates were calculated using $R$ software ( $R$ : A language and environment for statistical computing, https://www.R-project.org/).

\section{Results}

A technically successful procedure could be performed in all but two cases (technical success rate 14/16; 87.5\%). One of the failed cases was later managed by endoscopic glue injection 3 days post-BRTO attempt. The other case did not agree for any further endoscopic/vascular procedure. However, on telephonic follow-up at 3 months, he did not have any recurrence of GI bleeding.

Eleven patients required embolization of collateral veins with gelfoam slurry to prevent the runoff of the sclerosant into the systemic circulation. One patient required embolization of the collaterals ( $\boldsymbol{- \text { Fig. }}$ 4) with coils (Cook Medicals, USA).

The 24-hour postprocedure CT showed significant regression/complete thrombosis in 13/14 completed procedures (thrombosis rate of $92.9 \%$ ). One patient had a bout of massive hematemesis 2 hours after completion of a successful BRTO which was fatal. Probably, he had rebleed due to the increased pressure within the varices (due to occlusion of GRS which is the efferent for varices by the balloon) before adequate thrombosis could take place.

Follow-up CT at 3 months postprocedure in 13/14 surviving patients following a successful procedure showed no recanalization of GVs. No patient in this group reported any recurrence of GI bleeding in the follow-up period. However, one patient $(1 / 14)$ developed EVs which were managed by prophylactic endoscopic banding. Further, two patients developed mild increase in ascites (one of them is the patient mentioned above, who required banding for EVs). However, they were managed medically.

The single patient who underwent BRTO for refractory HE showed a decrease in serum ammonia from a preprocedure value of $155 \mu / \mathrm{dL}$ to $33 \mu / \mathrm{dL}$ at 1 -month postprocedure. Also, no recurrence of HE was noted.

The 3-, 6-, 9- and 12-month probability of overall survival rates were $87.5 \%, 80.8 \%, 80.8 \%$ and $80.8 \%$, respectively. In the same time period, probability of ascites-free survival rates were $92.3 \%, 82.1 \%, 82.1 \%$ and $82.1 \%$, respectively, and bleed-free survival rates were $87.5 \%, 87.5 \%, 87.5 \%$ and $87.5 \%$, respectively. - Fig. 5 shows the Kaplan-Meier curves for these parameters.

Two patients had an intraprocedure rupture of GRS, which was recognized as extravasation of contrast material into the retroperitoneal space. However, the procedure could be completed successfully in both these patients with no intraprocedure hemodynamic instability or postprocedure morbidity. One patient had partial splenic thrombosis in the postprocedure CT without any clinical manifestations. - Table 2 shows tips and tricks of BRTO procedure. 


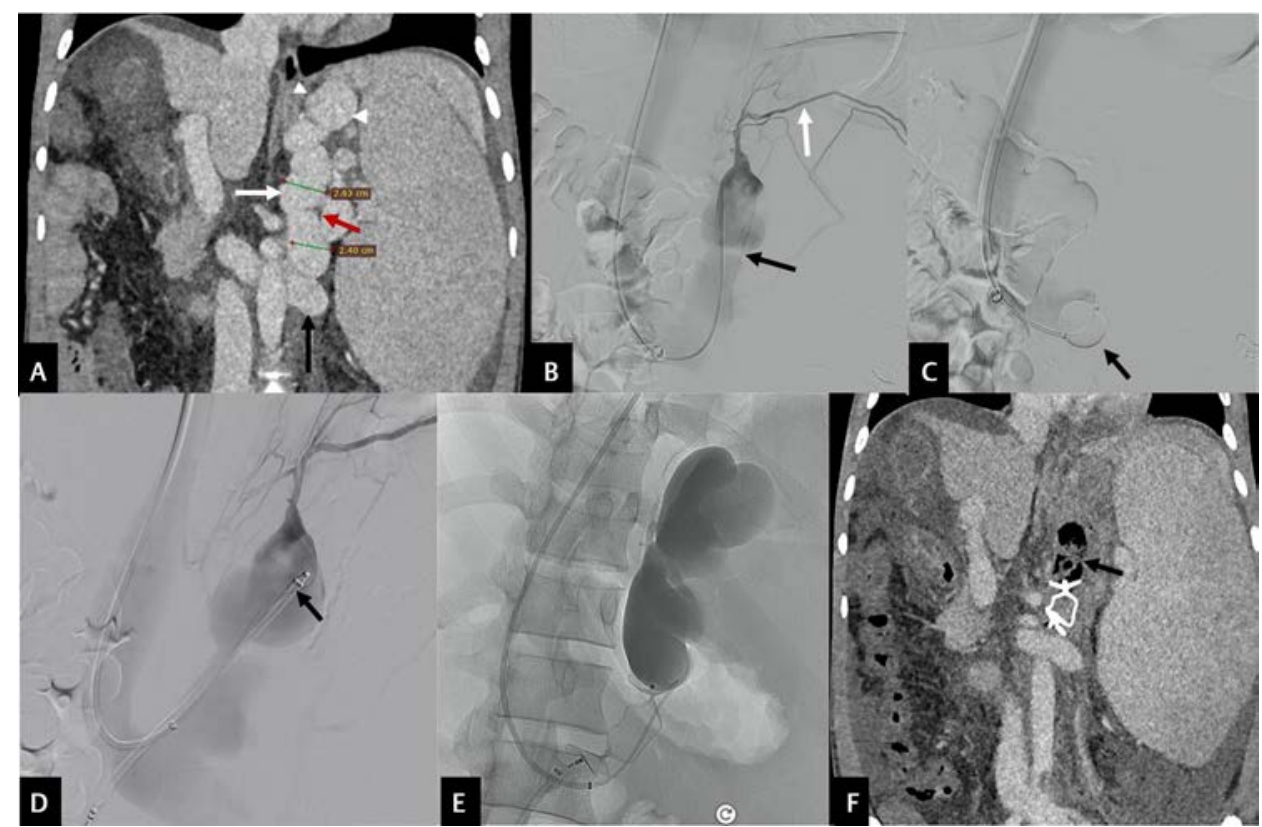

Fig. 3 A 37-year-old man presented with acute upper gastrointestinal (GI) bleed and large gastric varices (GVs) on endoscopy. CPS was B7. (A) The coronal reconstructed image of the CT portal venous phase showed a very large gastrorenal shunt (GRS) (white arrow) measuring 24 to $26 \mathrm{~mm}$ draining into the left renal vein (LRV) (black arrow). GVs are seen cranially (arrowheads). Note the constriction in the midpart of GRS (red arrow). (B) Cannulation of the GRS from a right jugular approach demonstrates the difficult anatomy in the form of the large size and an hourglass constriction (black arrow). Left inferior phrenic veins form the systemic runoff (white arrow). (C) Attempts to occlude the shunt using a $27 \mathrm{~mm}$ Equalizer balloon failed with the balloon falling into the LRV (black arrow). (D) The shunt was cannulated using a right femoral vein approach and a $10 \mathrm{Fr}$ sheath advanced with its tip (arrow) beyond the constriction. (E) A $24 \mathrm{~mm}$ Amplatzer Vascular Plug II was deployed in the GRS with its upper disc being above the constriction. Gelfoam slurry and STS was injected using the $5 \mathrm{Fr}$ catheter present by the side of the plug till stasis was achieved. The plug was deployed in this position. (F) 24-hour CT study shows thrombosis and air foci within the GRS (black arrow).

Table 2 Tips and tricks of BRTO procedure

1. Careful evaluation of CT venogram is required, in case of high clinical suspicion and negative conventional endoscopy to look for perigastric varices communicating with submucosal varices through perforators.

2. The GVs can be ablated in absence of GRS by identifying the efferent channel of GV into the systemic circulation. ${ }^{6,7}$

3. Significant contrast runoff during occlusion venogram from the varices into the systemic circulation require embolization before sclerosant injection (Fig. 4A-D). ${ }^{4}$

4. In the presence of SVT, BRTO should be preceded by SAE to decrease the portal inflow. ${ }^{4}$

5. The GRS lies medial to the AV. Care should be taken while advancing wire and injecting contrast to avoid AV injury and adrenal hemorrhage.

6. GRS is thin-walled and distended venous channel; therefore, care should be taken during manipulation to avoid inadvertent injury. In most of the cases, GRS rupture due to wire movement is self-limiting without significant retroperitoneal hemorrhage, but it may lead to collapse of the GRS.

7. During the injection of the sclerosant, reflux of the contrast into the SV and PV must be watched out for and avoided.

Abbreviations: AV, adrenal vein; BRTO, balloon-occluded retrograde transvenous obliteration; GRS, gastrorenal shunt; GV, gastric varices; PV, portal vein; SAE, splenic artery embolization; SV, splenic vein; SVT, splenic vein thrombosis.

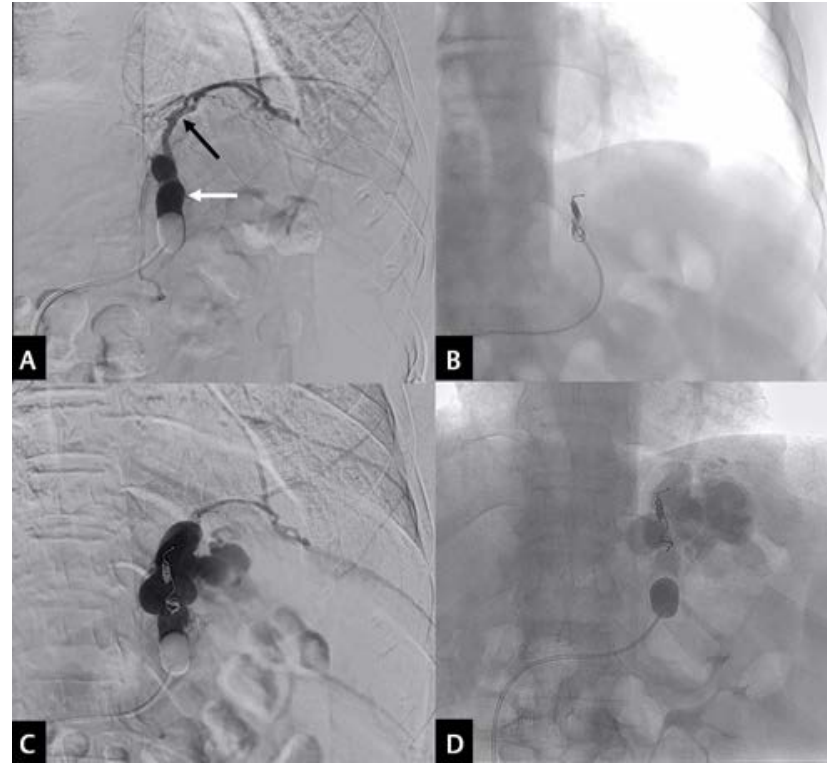

Fig. 4 (A) Initial occlusion venogram shows the GRS (white arrow) with fast systemic runoff into the left inferior phrenic vein (black arrow). (B) Coiling of the latter performed using two $3 \mathrm{~mm}$ size pushable coils. (C) Repeat venogram after coiling and gelfoam injection show good opacification of the gastric varices (GVs). (D) Sclerosant contrast stasis within the GVs. 

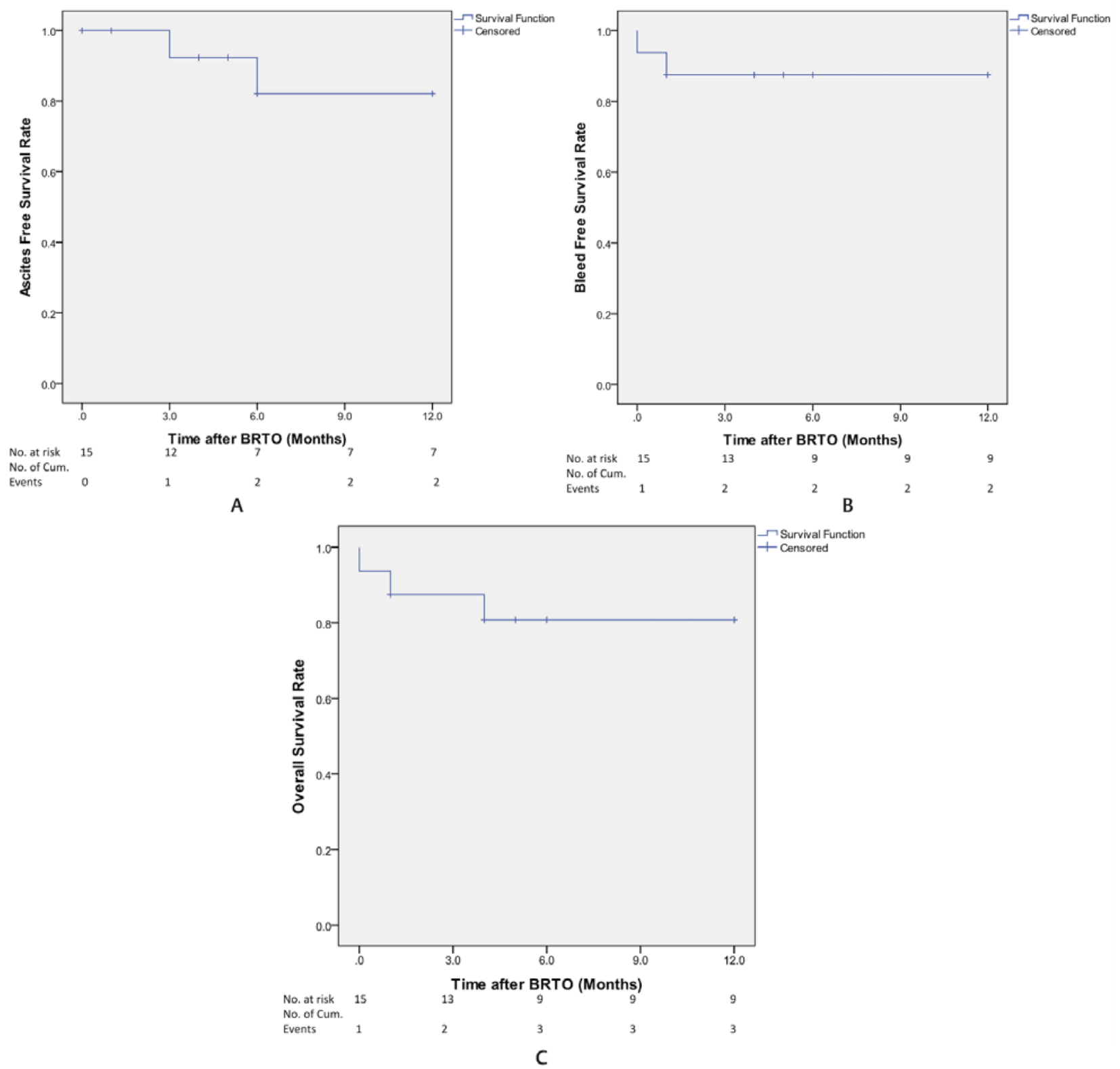

Fig. 5 The Kaplan-Meier curves for ascites-free survival (A), bleed-free survival (B), and overall survival rates (C) after balloon-occluded retrograde transvenous obliteration (BRTO).

\section{Discussion}

Upper GI endoscopy is the first-line diagnostic and therapeutic procedure for bleeding varices (EVs and GVs); however, it is not very effective for controlling bleeding from GVs. ${ }^{2,8-11} \mathrm{~A}$ transjugular intrahepatic portosystemic shunt (TIPS) is commonly performed to decompress the portal venous system if endoscopic interventions fail to arrest bleeding from varices. However, its efficacy in controlling bleeding GVs is much inferior compared with bleeding EVs. ${ }^{12,13}$ Occurrence or worsening of hepatic encephalopathy in 20 to $30 \%$ of patients who undergo TIPS is also an important factor for consideration. ${ }^{14}$

BRTO is an established form of treatment for GVs as an alternative to TIPS. ${ }^{15}$ Olson et al described the first attempt at balloon-occluded sclerotherapy of GRS for GVs, and
Kanagawa et al developed the modern form of this technique. ${ }^{16,17}$ During the past two decades, the technique for BRTO has evolved and it is presently a well-established minimally invasive treatment for GVs (both to control emergent bleeding or electively) as well as patients with medically refractory HE. . $^{3,18}$

The presence of EVs is not considered a contraindication for BRTO, since they can be easily managed by endoscopic band ligation in case they bleed/increase in size on close endoscopic follow-up. ${ }^{4}$ However, RTO of GVs is known to worsen EVs and ascites. In our study, only one of the 14 patients required treatment for EVs (endoscopic banding) at 1-month endoscopic follow-up after BRTO. In the presence of splenic vein thrombosis (SVT), BRTO can be performed after partial splenic artery embolization (SAE). ${ }^{4}$ 
One of the important components of RTO procedure is the choice of sclerosant used. Ethanolamine oleate was used in Japan but its use outside Japan is minimal, primarily because of its adverse effects such as hemolysis, hemoglobinuria and hemolysis-induced renal failure as well as the lack of availability of an effective antidote. ${ }^{19}$ The various other sclerosants used over the years are absolute alcohol, $\mathrm{N}$-butyl cyanoacrylate, STS, and polidocanol. The latter two are surfactants that cause endothelial damage with subsequent thrombosis of the vessels. ${ }^{20}$

Chang et al described safe use of STS liquid sclerotherapy in 17 patients for BRTO. Our results and complication rates are similar to those reported in their study, with a technical success rate of $87.5 \%$ and a clinical success rate of $92.9 \% .^{21}$

Pooled analysis of the published Indian studies revealed a clinical success rate of $100 \%$ (95\% CI: 0.95 to 1.0; both fixed and random effect model) ( - Fig. 6). . $^{3,22-25}$

Pooled analysis of the published Indian studies revealed survival rate at 1 year among patients undergoing BRTO of $97 \%$ (95\% CI: 0.91 to 1.0 ) and $98 \%$ (95\% CI:0.89 to 1.0 ) by

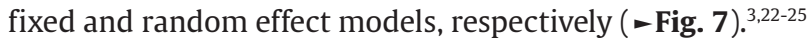

To our knowledge, there are two other large studies from the Indian subcontinent, describing the role of BRTO in patients with bleeding GVs or HE.,25 The sclerosant used by authors in both these studies was a mixture of air, STS, and lipiodol in a ratio 3:2:1. In our study, no lipiodol was used and this entails cost saving. Intraprocedural balloon rupture is also not seen in any of our cases.

The limitations of our study include the retrospective design and small sample size. The results need to be followed-up by doing a prospective study with the recruitment of a larger sample size. With the advent of EUS-guided coil and glue injection being done for GVs, a randomized study should be done to compare the efficacy and safety profile of the two procedures.

In conclusion, RTO is a safe and effective minimally invasive treatment in a select group of patients with GVs who have active or intermittent bleeding, are at high risk of bleeding due to the size of varices, or have refractory HE.

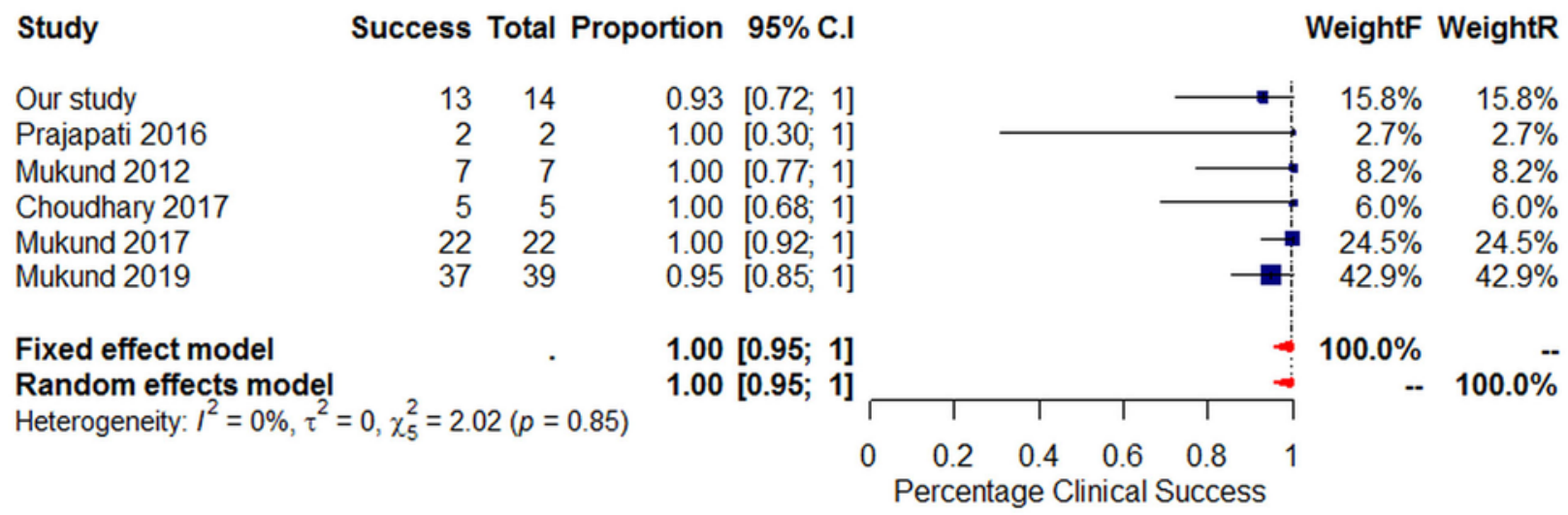

Fig. 6 Pooled analysis of the clinical success rate for balloon-occluded retrograde transvenous obliteration (BRTO) from published Indian studies.

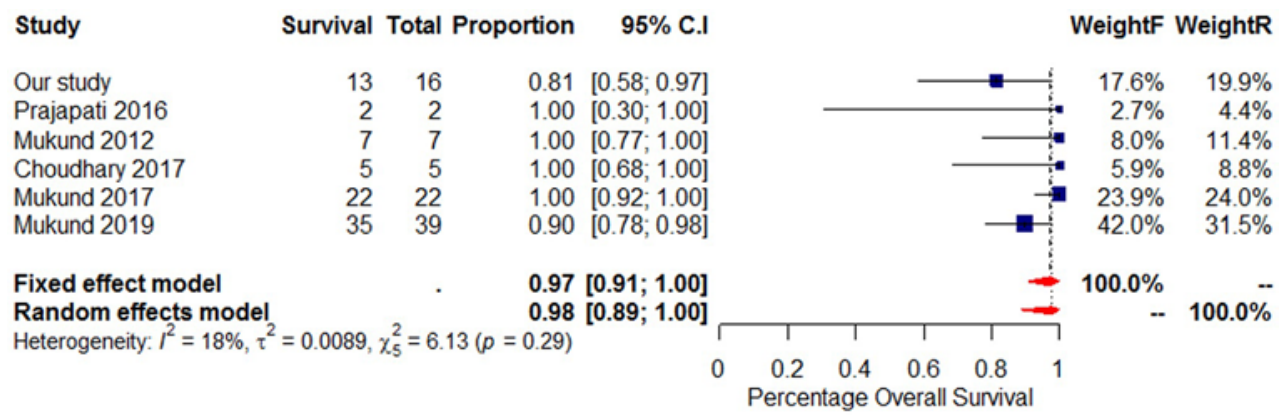

Fig. 7 Pooled analysis for survival rate at 1 year following balloon-occluded retrograde transvenous obliteration (BRTO) from published Indian studies. 


\section{Conflict of Interest}

None declared.

\section{Acknowledgment}

The authors are thankful to Mr. Mahesh for the drawing of $\sim$ Fig. 1.

\section{References}

1 Sarin SK, Lahoti D, Saxena SP, Murthy NS, Makwana UK. Prevalence, classification and natural history of gastric varices: a long-term follow-up study in 568 portal hypertension patients. Hepatology 1992;16(6):1343-1349

2 TrudeauW, Prindiville T. Endoscopic injection sclerosis in bleeding gastric varices. Gastrointest Endosc 1986;32(4):264-268

3 Mukund A, Chalamarla LK, Singla N, Shasthry SM, Sarin SK. Intractable hepatic encephalopathy in cirrhotic patients: mid-term efficacy of balloon-occluded retrograde portosystemic shunt obliteration. Eur Radiol 2020;30(6):3462-3472

4 Saad WE, Kitanosono T, Koizumi J, Hirota S. The conventional balloon-occluded retrograde transvenous obliteration procedure: indications, contraindications, and technical applications. Tech Vasc Interv Radiol 2013;16(2):101-151

5 Sacks D, McClenny TE, Cardella JF, Lewis CA. Society of Interventional Radiology clinical practice guidelines. J Vasc Interv Radiol 2003;14(9 Pt 2):S199-S202

6 Kameda N, Higuchi K, Shiba M, et al. Management of gastric fundal varices without gastro-renal shunt in 15 patients. World J Gastroenterol 2008;14(3):448-453

7 Khera PS, Myungsu L, Joonsung C. Balloon occluded retrograde transvenous obliteration for bleeding gastric varices: Eyes see what the mind knows. Indian J Radiol Imaging 2017;27(1):100-104

8 Sarin SK. Long-term follow-up of gastric variceal sclerotherapy: an eleven-year experience. Gastrointest Endosc 1997;46(1):8-14

9 Roesch W, Rexroth G. Pulmonary, cerebral and coronary emboli during bucrylate injection of bleeding fundic varices. Endoscopy 1998;30(8):S89-S90

10 Hwang SS, Kim HH, Park SH, et al. N-butyl-2-cyanoacrylate pulmonary embolism after endoscopic injection sclerotherapy for gastric variceal bleeding. J Comput Assist Tomogr 2001;25(1):16-22

11 Binmoeller KF. Endoscopic Ultrasound-Guided Coil and Glue Injection for Gastric Variceal Bleeding. Gastroenterol Hepatol (N Y) 2018;14(2):123-126

12 Sanyal AJ, Freedman AM, Luketic VA, et al. The natural history of portal hypertension after transjugular intrahepatic portosystemic shunts. Gastroenterology 1997;112(3):889-898
13 Somberg KA. TIPS: safe, effective, better? Am J Gastroenterol 1997;92(9):1412-1416

14 Riggio O, Nardelli S, Moscucci F, Pasquale C, Ridola L, Merli M. Hepatic encephalopathy after transjugular intrahepatic portosystemic shunt. Clin Liver Dis 2012;16(1):133-146

15 Saad WE, Simon PO Jr, Rose SC. Balloon-occluded retrograde transvenous obliteration of gastric varices. Cardiovasc Intervent Radiol 2014;37(2):299-315

16 Olson E, Yune HY, Klatte EC. Transrenal-vein reflux ethanol sclerosis of gastroesophageal varices. Am J Roentgenol 1984;143(3):627-628

17 Kanagawa H, Mima S, Kouyama H, Gotoh K, Uchida T, Okuda K. Treatment of gastric fundal varices by balloon-occluded retrograde transvenous obliteration. J Gastroenterol Hepatol 1996;11(1):51-58

18 Saad WE, Sabri SS. Balloon-occluded retrograde transvenous obliteration (BRTO): technical results and outcomes. Semin Intervent Radiol 2011;28(3):333-338

19 Kiyosue $\mathrm{H}$, Mori $\mathrm{H}$, Matsumoto S, Yamada Y, Hori Y, Okino Y. Transcatheter obliteration of gastric varices: Part 2. Strategy and techniques based on hemodynamic features. Radiographics 2003;23(4):921-937

20 Cameron E, Chen T, Connor DE, Behnia M, Parsi K. Sclerosant foam structure and stability is strongly influenced by liquid air fraction. Eur J Vasc Endovasc Surg 2013;46(4):488-494

21 Chang IS, Park SW, Kwon SY, et al. Efficacy and safety of balloon-occluded retrograde transvenous obliteration with sodium tetradecyl sulfate liquid sclerotherapy. Korean J Radiol 2016;17(2):224-229

22 Prajapati R, Ranjan P, Gupta A, Yadav AK. balloon-occluded retrograde transvenous obliteration (BRTO): a novel method of control of bleeding from post-glue ulcer over gastric varices. Report of two cases and review of literature. J Clin Exp Hepatol 2016;6(4):326-330

23 Mukund A, Rajesh S, Arora A, Patidar Y, Jain D, Sarin SK. Efficacy of balloon-occluded retrograde transvenous obliteration of large spontaneous lienorenal shunt in patients with severe recurrent hepatic encephalopathy with foam sclerotherapy: initial experience. J Vasc Interv Radiol 2012;23(9):1200-1206

24 Choudhary NS, Baijal SS, Saigal S, et al. Results of portosystemic shunt embolization in selected patients with cirrhosis and recurrent hepatic encephalopathy. J Clin Exp Hepatol 2017;7(4):300-304

25 Mukund A, Deogaonkar G, Rajesh S, Shasthry SM, Sarin SK. Safety and efficacy of sodium tetradecyl sulfate and lipiodol foam in balloon-occluded retrograde transvenous obliteration (BRTO) for large porto-systemic shunts. Cardiovasc Intervent Radiol 2017;40(7):1010-1016 